\title{
The World's Changing Human Capital Stock: Multi- State Population Projections by Educational Attainment
}

\author{
Wolfgang Lutz \\ International Institute for Applied Systems Analysis, Laxenburg, Austria \\ Anne Goujon \\ International Institute for Applied Systems Analysis, Laxenburg, Austria
}

RP-01-11

June 2001

Reprinted from Population and Development Review 27 (2): 323-339 (June 2001) 
IIASA Reprints make research conducted at the International Institute for Applied Systems Analysis more accessible to a wider audience. They reprint independently reviewed articles that have been previously published in journals. Views or opinions expressed herein do not necessarily represent those of the Institute, its National Member Organizations, or other organizations supporting the work.

Reprinted with permission from Population and Development Review 27(2): 323-339 (June 2001) Copyright (C) 2001

All rights reserved. No part of this publication may be reproduced or transmitted in any form or by any means, electronic or mechanical, including photocopy, recording, or any information storage or retrieval system, without permission in writing from the copyright holder. 


\title{
The World's Changing Human Capital Stock: Multi-State Population Projections by Educational Attainment*
}

\author{
Wolfgang Lutz and Anne Goujon
}

EDUCATION IS GENERALLY assumed to have far-reaching beneficial consequences. At the individual level more education tends to imply better health, wider economic opportunities, and greater autonomy, especially for women (Federici et al. 1993; Jejeebhoy 1995). At the aggregate level the educational composition of the population has long been considered a key factor in economic, institutional, and social development (Bellew et al. 1992; Benavot 1989; Hadden and London 1996) and in the rate of technological progress (Grossman and Helpman 1991; Romer 1992). The extensive theoretical and empirical literature on the relationship between human capital formation and various aspects of development is not reviewed here.' Instead, this research note demonstrates the feasibility of multi-state cohort component population projections for groups defined by different educational attainment. With the increasing importance of education in a knowledge-based economy, this approach can make a contribution not only to the field of demography, but also to long-range economic planning.

\section{The multi-state approach}

The increasing awareness over the past decade of the importance of human capital in development has stimulated attempts to estimate and project the educational composition of the population. Most empirical studies have approximated educational stocks in terms of enrollment ratios or illiteracy rates (Mankiw et al. 1992; Romer 1989). What is needed, however, is a complete matrix of the composition of the population by age, sex, and levels of educational attainment for different points in time. Many attempts to measure human capital stock have failed to meet this goal because of problems with country-level data and the lack of appropriate demographic methodologies (Ahuja and Filmer 1995; Barro and Lee 1993; Dubey and King 1994; Kyriacou 1991; Nehru et al. 1993; Psacharopoulos and Arrigada 1986, 1992). Ahuja and Filmer (1995) came nearest to our approach by taking existing UN population projections and superimposing onto them an educational distribution estimated for two broad age groups (ages 6-24 and 25 and older) from given sets of enrollment ratios and UNESCO projections. Using this approach they projected the educational composition (for four educational groups) for 71 developing countries. Apart from the lack of more detailed information by age, this approach was also of a static nature: it

1 An extensive international bibliography is given in Brock and Cammish (1997).

* Reprint from Population and Development Review, 27 (2), pp. 323-339 (June 2001). New York. NY: The Population Council. Reprinted with the permission of the Population Council 
did not allow the educational composition of the population to influence fertility despite the marked educational fertility differentials found in most developing countries.

In this study we apply the demographic methodology of multi-state population projection to the task. This method is based on a multi-dimensional expansion of the life table (increment-decrement tables) and of the cohort-component projection method developed at the International Institute for Applied Systems Analysis (IIASA) during the 1970s (Keyfitz 1985; Rogers 1975). The multi-state model divides the population by age and sex into "states." Originally states were conceived of as geographic units, with the movements between the states being migration streams. But a "state" can also reflect any other clearly defined subgroup of the population, for example groups with different educational attainment, with the movements then becoming educational transition rates. The projection of human capital stocks by age and sex is an ideal example for the application of the multidimensional cohort-component model, because education tends to be acquired at younger ages and then simply moves along cohort lines. Change in the educational composition of the total population (aged 15 and older) is typically caused by the depletion (through mortality) of less-educated older cohorts and the entry of more-educated younger cohorts.

Figure 1 shows the specific structure of the multi-state model chosen for this study. It subdivides the population into four distinct groups according to educational attainment. Each subpopulation is further stratified by age (five-year age groups) and sex, and can be represented through a separate population pyramid. The key parameters of the model are three sets of age- and sex-specific educational transition rates, that is, the age-specific probabilities for young men or women to move, for example, from the category of primary educational attainment to that of secondary attainment. Although this model can handle transitions at any age, for example as a result of adult education campaigns, in reality transitions at older ages are very rare. Transitions here are concentrated in the age range below 25 years depending on the kind of transition. Another important feature gives this model a dynamic element: it considers different fertility rates for different educational groups. Hence, even with constant status-specific fertility, a change in the relative size of the educational subpopulation results in changes in the fertility rate of the total population. This feature significantly influences the results discussed in the data section below. Migration and mortality are only considered by age and sex in this application. While for international migration we assumed a hypothetical distribution by education, we did not feel in the position to do so for mortality. ${ }^{2}$ As more empirical information becomes available, empirically founded educational differentials may also be assumed for these two components of change.

Social science tells us that not only fertility rates, but also school enrollment rates (flows) tend to depend on the educational composition (stocks). There is much evidence of intergenerational transmission of education. For this reason we also run some special scenarios that take account of such feedbacks. It is useful here to distinguish between firstorder feedbacks that represent compositional effects resulting from educational fertility differentials, and second-order feedbacks that represent behavioral responses to changing stocks. Although there is little reliable empirical evidence to model such responses at the

2 Data are available from surveys on infant mortality by education of the mother, but neither this information nor the information about surviving relatives is sufficient to study the educational level of the person who dies. As discussed in Lutz et al. (1999), mortality differentials have significant effects only for the size of the elderly population. They are less relevant for the study of the working-age population. 
Figure 1: Structure of the multi-state population projection model by level of education

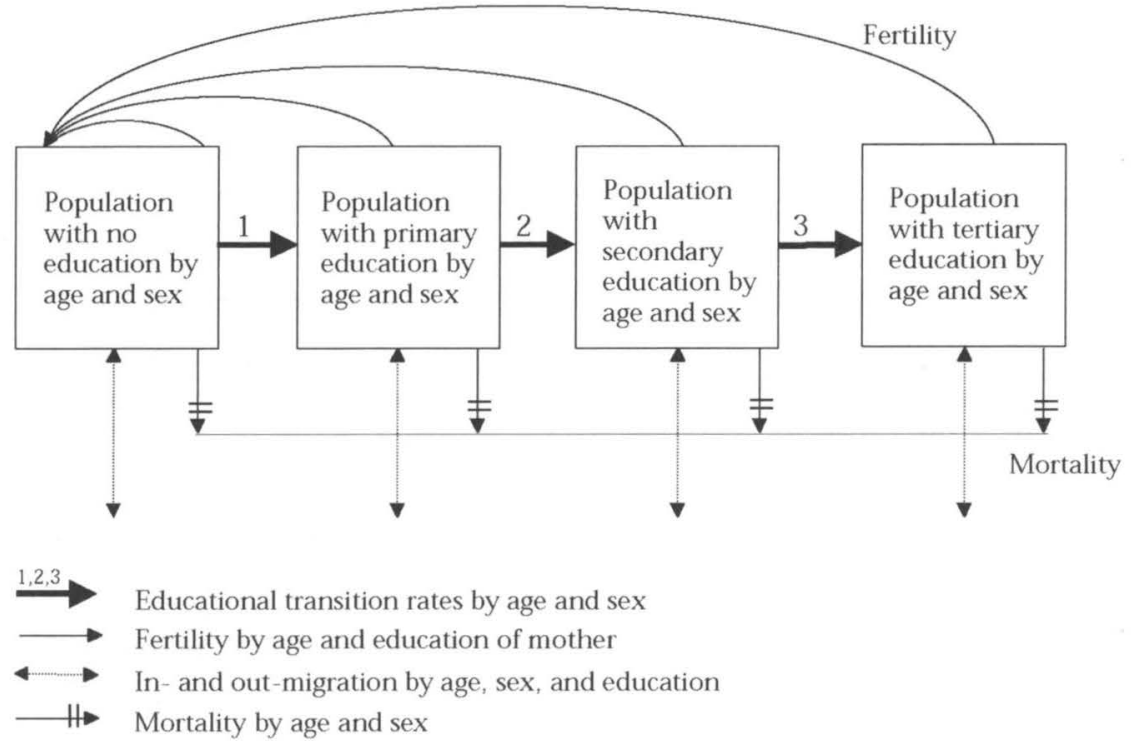

macro level, we will describe an experimental scenario incorporating such second-order feedbacks. ${ }^{3}$

It is evident that under such a setup, educational projections cannot be simply superimposed onto given population projections, as has been done in previous studies. Population projections must be carried out as an integral part of the exercise, since alternative educational scenarios will result in alternative fertility trends. The educational projections presented here, therefore, expand on the demographic assumptions of IIASA's newest and still unpublished world population projections, which will document our more extensive projections (Lutz 2001). Our projections pick up methodological recommendations made in Frontiers of Population Forecasting (Lutz et al. 1999). The substantive fertility, mortality, and migration assumptions are largely based on recommendations in the National Academy of Sciences report entitled Beyond Six Billion (Bongaarts and Bulatao 2000) and are specified in detail in Lutz (2001).

Population projections by level of education are a logical next step in improving population forecasts and making them more relevant. As discussed in Lutz et al. (1999) adding education to age and sex as an explicit demographic dimension in population forecasting also affects the demographic output parameters themselves because a significant source of so-far-unobserved heterogeneity is being observed and explicitly endogenized. It may, therefore, be considered an improvement, even of the purely demographic output parameters of the projection. More importantly, however, the future educational composition of the population is of interest in its own right.

3 We thank an anonymous referee for encouraging us to present such a scenario.

4 For a detailed listing of countries by region, see Lutz (1996). 
Table 1: Estimated share of the population above 15 years of age (in \%) by education and sex in 2000 , and projected shares in 2030 according to the "constant" and "American" scenarios

\begin{tabular}{|c|c|c|c|c|c|c|c|c|c|c|c|c|c|c|c|c|c|c|c|c|c|c|c|c|}
\hline \multirow[b]{3}{*}{ Region } & \multicolumn{8}{|c|}{2000} & \multicolumn{8}{|c|}{2030 - "Constant" scenario } & \multicolumn{8}{|c|}{2030 - "American" scenario } \\
\hline & \multicolumn{2}{|c|}{$\begin{array}{c}\text { No } \\
\text { education }\end{array}$} & \multicolumn{2}{|c|}{ Primary } & \multicolumn{2}{|c|}{ Secondary } & \multicolumn{2}{|c|}{ Tertiary } & \multicolumn{2}{|c|}{$\underset{\text { education }}{\text { No }}$} & \multicolumn{2}{|c|}{ Primary } & \multicolumn{2}{|c|}{ Secondary } & \multicolumn{2}{|c|}{ Tertiary } & \multicolumn{2}{|c|}{$\begin{array}{c}\text { No } \\
\text { education }\end{array}$} & \multicolumn{2}{|c|}{ Primary } & \multicolumn{2}{|c|}{ Secondary } & \multicolumn{2}{|c|}{ Tertiary } \\
\hline & $\mathbf{M}$ & $\mathbf{F}$ & $\mathbf{M}$ & $\mathbf{F}$ & $\mathbf{M}$ & $\mathbf{F}$ & $\mathbf{M}$ & F & $\mathbf{M}$ & $\mathbf{F}$ & $\mathbf{M}$ & $F$ & $\mathbf{M}$ & $\mathbf{F}$ & $\mathbf{M}$ & $\mathbf{F}$ & $\mathbf{M}$ & $\mathbf{F}$ & $\mathbf{M}$ & $\mathbf{F}$ & $\mathbf{M}$ & $\mathbf{F}$ & $\mathbf{M}$ & $\mathbf{F}$ \\
\hline North Africa & 33 & 55 & 21 & 17 & 32 & 20 & 15 & 8 & 14 & 34 & 28 & 21 & 44 & 35 & 14 & 9 & 13 & 30 & 21 & 17 & 44 & 36 & 22 & 17 \\
\hline $\begin{array}{l}\text { Sub-Saharan } \\
\text { Africa }\end{array}$ & 33 & 52 & 42 & 34 & 21 & 12 & 3 & 1 & 20 & 36 & 52 & 44 & 25 & 19 & 3 & 1 & 17 & 30 & 38 & 33 & 33 & 28 & 12 & 10 \\
\hline Northern America & 1 & 1 & 7 & 7 & 49 & 51 & 44 & 42 & 1 & 1 & 6 & 6 & 49 & 47 & 44 & 46 & 1 & 1 & 6 & 6 & 48 & 47 & 45 & 46 \\
\hline Latin America & 12 & 15 & 39 & 39 & 39 & 37 & 11 & 9 & 3 & 4 & 35 & 35 & 51 & 50 & 11 & 11 & 3 & 4 & 28 & 29 & 49 & 48 & 20 & 19 \\
\hline Central Asia & 1 & 4 & 4 & 7 & 77 & 77 & 17 & 13 & 0 & 0 & 1 & 1 & 84 & 86 & 15 & 13 & 0 & 0 & 1 & 1 & 72 & 74 & 26 & 25 \\
\hline West Asia & 19 & 34 & 39 & 33 & 29 & 23 & 14 & 10 & 10 & 25 & 35 & 29 & 44 & 37 & 11 & 9 & 9 & 22 & 28 & 24 & 43 & 38 & 20 & 17 \\
\hline South Asia & 39 & 66 & 23 & 17 & 32 & 15 & 5 & 2 & 12 & 37 & 48 & 44 & 33 & 15 & 7 & 4 & 12 & 34 & 35 & 32 & 38 & 25 & 14 & 10 \\
\hline China and $\mathrm{CPA}^{\mathrm{a}}$ & 10 & 26 & 36 & 37 & 51 & 35 & 4 & 2 & 2 & 7 & 21 & 29 & 71 & 60 & 6 & 4 & 2 & 7 & 23 & 30 & 60 & 50 & 15 & 13 \\
\hline Pacific Asia & 23 & 33 & 37 & 36 & 31 & 24 & 9 & 6 & 9 & 15 & 42 & 42 & 38 & 35 & 11 & 8 & 9 & 14 & 33 & 34 & 40 & 37 & 17 & 15 \\
\hline Pacific $O E C D^{b}$ & 0 & 0 & 19 & 22 & 54 & 55 & 26 & 23 & 0 & 0 & 8 & 9 & 62 & 64 & 29 & 26 & 0 & 0 & 8 & 9 & 58 & 60 & 33 & 31 \\
\hline Western Europe & 5 & 8 & 23 & 28 & 53 & 49 & 19 & 15 & 1 & 3 & 11 & 14 & 57 & 54 & 30 & 30 & 1 & 3 & 11 & 14 & 56 & 54 & 31 & 29 \\
\hline Eastern Europe ${ }^{c}$ & 2 & 3 & 30 & 39 & 58 & 49 & 10 & 8 & 0 & 0 & 16 & 19 & 73 & 69 & 11 & 11 & 0 & 0 & 14 & 18 & 67 & 64 & 19 & 18 \\
\hline $\begin{array}{l}\text { Former Soviet } \\
\text { Union }\end{array}$ & 1 & 0 & 23 & 27 & 60 & 57 & 17 & 16 & 0 & 0 & 10 & 11 & 71 & 68 & 19 & 21 & 0 & 0 & 9 & 10 & 66 & 64 & 25 & 25 \\
\hline World & 18 & 31 & 30 & 28 & 42 & 32 & 11 & 8 & 8 & 18 & 33 & 32 & 48 & 40 & 12 & 10 & 7 & 16 & 26 & 26 & 48 & 41 & 19 & 17 \\
\hline
\end{tabular}

${ }^{3}$ China and centrally planned Asia includes Cambodia, China, Hong Kong, Laos, Mongolia, North Korea, Taiwan, and Vietnam.

' Australia, Japan, New Zealand.

'Albania, Bosnia-Herzegovina, Bulgaria, Croatia, Czech Republic, Hungary, Macedonia, Poland, Romania, Slovak Republic, Slovenia, Yugoslavia.

$\mathrm{M}=$ male $; \mathrm{F}=$ female 
Table 2: Estimated population above 15 years of age (in millions) by education and sex in 2000 , and projected population in 2030 according to the "constant" and "American" scenarios

\begin{tabular}{|c|c|c|c|c|c|c|c|c|c|c|c|c|c|c|c|c|c|c|c|c|c|c|c|c|}
\hline \multirow[b]{3}{*}{ Region } & \multicolumn{8}{|c|}{2000} & \multicolumn{8}{|c|}{2030 - “Constant" scenario } & \multicolumn{8}{|c|}{2030 - “American" scenario } \\
\hline & \multicolumn{2}{|c|}{$\begin{array}{c}\text { No } \\
\text { education }\end{array}$} & \multicolumn{2}{|c|}{ Primary } & \multicolumn{2}{|c|}{ Secondary } & \multicolumn{2}{|c|}{ Tertiary } & \multicolumn{2}{|c|}{$\begin{array}{c}\text { No } \\
\text { education }\end{array}$} & \multicolumn{2}{|c|}{ Primary } & \multicolumn{2}{|c|}{ Secondary } & \multicolumn{2}{|c|}{ Tertiary } & \multicolumn{2}{|c|}{$\begin{array}{c}\text { No } \\
\text { education }\end{array}$} & \multicolumn{2}{|c|}{ Primary } & \multicolumn{2}{|c|}{ Secondary } & \multicolumn{2}{|c|}{ Tertiary } \\
\hline & $\mathbf{M}$ & $\mathbf{F}$ & $\mathbf{M}$ & $\mathbf{F}$ & $\mathbf{M}$ & $\mathbf{F}$ & $\mathbf{M}$ & $\mathbf{F}$ & $\mathbf{M}$ & $\mathbf{F}$ & $\mathbf{M}$ & $\mathbf{F}$ & $\mathbf{M}$ & $\mathbf{F}$ & $\mathbf{M}$ & $\mathbf{F}$ & $\mathbf{M}$ & $\mathbf{F}$ & $\mathbf{M}$ & $\mathbf{F}$ & $\mathbf{M}$ & $\mathbf{F}$ & $\mathbf{M}$ & $\mathbf{F}$ \\
\hline North Africa & 18 & 31 & 12 & 9 & 18 & 11 & 8 & 5 & 14 & 34 & 28 & 21 & 44 & 35 & 14 & 9 & 13 & 30 & 21 & 17 & 44 & 36 & 22 & 17 \\
\hline Sub-Saharan Africa & 56 & 90 & 71 & 59 & 35 & 21 & 6 & 2 & 71 & 128 & 180 & 157 & 87 & 69 & 10 & 5 & 60 & 107 & 132 & 118 & 115 & 99 & 41 & 34 \\
\hline Northem America & 1 & 1 & 8 & 8 & 59 & 64 & 53 & 53 & 2 & 2 & 10 & 9 & 76 & 79 & 69 & 78 & 2 & 2 & 10 & 9 & 75 & 79 & 70 & 78 \\
\hline Latin America & 21 & 27 & 67 & 69 & 67 & 67 & 18 & 16 & 8 & 11 & 97 & 103 & 141 & 147 & 30 & 32 & 8 & 11 & 78 & 84 & 136 & 141 & 54 & 56 \\
\hline Central Asia & 0 & 1 & 1 & 1 & 14 & 14 & 3 & 2 & 0 & 0 & 0 & 0 & 26 & 29 & 5 & 4 & 0 & 0 & 0 & 0 & 23 & 25 & 8 & 8 \\
\hline West Asia & 10 & 17 & 21 & 17 & 16 & 11 & 8 & 5 & 11 & 28 & 39 & 32 & 50 & 41 & 13 & 10 & 10 & 24 & 31 & 26 & 49 & 42 & 23 & 19 \\
\hline South Asia & 180 & 284 & 108 & 74 & 149 & 65 & 23 & 9 & 96 & 279 & 370 & 329 & 250 & 113 & 52 & 27 & 93 & 252 & 269 & 240 & 296 & 185 & 111 & 71 \\
\hline China and CPA & 52 & 133 & 192 & 191 & 270 & 180 & 19 & 10 & 12 & 46 & 141 & 195 & 477 & 408 & 41 & 29 & 13 & 47 & 152 & 202 & 405 & 342 & 101 & 88 \\
\hline Pacific Asia & 39 & 55 & 61 & 61 & 51 & 41 & 14 & 11 & 24 & 37 & 105 & 110 & 96 & 90 & 26 & 21 & 23 & 36 & 84 & 88 & 102 & 96 & 44 & 40 \\
\hline Pacific OECD ${ }^{b}$ & 0 & 0 & 12 & 14 & 33 & 36 & 16 & 15 & 0 & 0 & 5 & 6 & 40 & 44 & 19 & 18 & 0 & 0 & 5 & 6 & 37 & 41 & 21 & 21 \\
\hline Western Europe & 8 & 14 & 42 & 53 & 96 & 94 & 35 & 29 & 3 & 6 & 23 & 29 & 114 & 112 & 59 & 62 & 3 & 6 & 22 & 29 & 112 & 113 & 62 & 61 \\
\hline Eastern Europec & 1 & 2 & 14 & 20 & 28 & 25 & 5 & 4 & 0 & 0 & 8 & 10 & 35 & 36 & 5 & 6 & 0 & 0 & 7 & 9 & 32 & 33 & 9 & 9 \\
\hline $\begin{array}{l}\text { Former Soviet } \\
\text { Union }\end{array}$ & 1 & 0 & 20 & 28 & 53 & 59 & 15 & 16 & 0 & 0 & 8 & 11 & 61 & 67 & 16 & 21 & 0 & 0 & 7 & 10 & 56 & 64 & 21 & 25 \\
\hline World & 386 & 656 & 628 & 606 & 888 & 690 & 224 & 179 & 241 & 570 & 1.014 & 1.013 & 1.498 & 1.272 & 359 & 322 & 224 & 514 & 819 & 839 & 1.481 & 1.295 & 588 & 528 \\
\hline
\end{tabular}

a For countries included in this region see note to Table 1 .

$\mathrm{M}=$ male; $\mathrm{F}=$ female 


\section{Data on education}

The educational projections are carried out at the level of 13 world regions. ${ }^{4}$ For each region the population is split into four groups according to educational attainment. The four education categories, which are meant to follow the international standard classification of education (ISCED) and reflect data availability, are defined as follows:

1) No education: Applies to those who have completed less than one year of formal schooling. ${ }^{5}$

2) Primary education: Includes all those who completed at least one year of education at the first level (primary) but did not go on to second-level studies.

3) Secondary education: Consists of those who moved to the second level of education, whether or not they completed the full course, but did not proceed to studies at the tertiary level.

4) Tertiary education: All those who undertook third-level studies, whether or not they completed the full course.

The following procedures were applied for estimating the starting population for the year 2000 by age, sex, and education for the 13 regions. First, the population by age and sex for each region was estimated by aggregating the specific country data for the year 2000 according to the medium variant ${ }^{6}$ of the estimates made by the United Nations (1999); next, the educational composition of the population by age and sex for 2000 was estimated based on individual country data, which mostly stem from census and survey information. The individual countries were chosen so as to be representative of their region and to result in maximum coverage of the populations of the respective regions. For details, see the Appendix.

These regional estimates, shown in Tables 1 and 2, yield the educational composition of the world population in 2000 . Of the total population of slightly more than 6 billion, 4.3 billion men and women are above age 15 . Of these, $18 \%$ of all men and $31 \%$ of all women are still without any formal education. At the high end, $11 \%$ of the world's adult men and $8 \%$ of adult women have received some tertiary education. Table 1 shows that these global averages mask enormous regional differences. For women with some tertiary education, the range is from $42 \%$ in Northern America to $1 \%$ in sub-Saharan Africa. In South Asia (mostly India) $66 \%$ of women and 39\% of men are still without any formal education, while in Pacific Asia (mostly Southeast Asia) these percentages already have declined to $33 \%$ and $23 \%$, respectively, showing a much smaller gender gap. The smallest gender gap in education is found in Northern America, followed by Europe.

Fertility tends to vary strongly with the level of female education in most countries, particularly in those that are in the midst of the demographic transition. This information can be derived from a wealth of fertility surveys (Demographic and Health Surveys, Fertility and Family Surveys, and others) that have been conducted in a large number of countries around the world. The widest fertility differentials by educational level are observed

5 In certain instances where data were lacking, illiteracy data have been used to estimate the "no education" category. Since it may take up to four years of primary education to achieve literacy, this approach tends to overestimate the proportion in the "no education" category.

6 Because the starting year 2000 is more recent than the dates of the last empirical information available, this estimation of starting conditions involves projections for a few years. Such projections generally followed the assumptions made in the UN median variant for 1995-2000. 
Table 3: Total fertility rates by region and by women's level of educational attainment, 1995 2000

\begin{tabular}{|l|c|c|c|c|c|}
\hline Region & Total & $\begin{array}{c}\text { No } \\
\text { education }\end{array}$ & Primary & Secondary & Tertiary \\
\hline North Africa & 3.56 & 4.50 & 3.23 & 2.46 & 2.27 \\
Sub-Saharan Africa & 5.52 & 6.13 & 5.53 & 3.99 & 2.35 \\
Northern America & 1.95 & 1.93 & 1.93 & 1.95 & 1.96 \\
Latin America & 2.69 & 4.93 & 3.40 & 2.14 & 1.61 \\
Central Asia & 3.16 & n.a. & 1.98 & 3.30 & 2.52 \\
West Asia & 4.14 & 4.94 & 4.44 & 3.54 & 2.57 \\
South Asia & 3.38 & 3.80 & 3.34 & 2.54 & 2.18 \\
China and CPA & 1.88 & 2.43 & 2.14 & 1.63 & 1.08 \\
Pacific Asia & 2.53 & 2.55 & 2.85 & 2.36 & 1.88 \\
Pacific OECD & 1.50 & 1.50 & 1.50 & 1.50 & 1.50 \\
Western Europe & 1.64 & 2.24 & 1.71 & 1.64 & 1.52 \\
Eastern Europe & 1.44 & 1.62 & 1.64 & 1.44 & 1.15 \\
Former Soviet Union & 1.41 & 1.29 & 1.30 & 1.43 & 1.39 \\
\hline
\end{tabular}

${ }^{a}$ For countries included in this region see note to Table 1.

n.a. = not available.

Source: Authors' calculations from primary data (see Appendix)

in Africa (for extreme cases in Benin and Togo, the DHS data show that women without formal education have well above 6 children, whereas women with some tertiary education have only 1.3 on average) and in parts of Latin America (e.g., Guatemala 7.1 versus 1.8, Bolivia 7.1 versus 2.2, Brazil 5.0 versus 1.5). ${ }^{7}$ Asia and Europe have an intermediate position, and Northern America shows virtually no fertility differentials by educational level.

Table 3 lists the educational fertility differentials as estimated on the basis of countryspecific data for the 13 regions for $1995-2000 .^{8}$ Differentials by education for the 13 regions were estimated using all available information on the level of individual countries," including qualitative information for the countries without good data. The estimated relative educational differentials were then applied to the total fertility rate (TFR) and to the age-specific fertility rates for the 13 regions in the context of the multi-state model described above.

On the assumption that interregional migrants are usually better educated than the general population, migrants were allocated according to the following shares: $10 \%$ to the noeducation category, $40 \%$ to the primary education category, $40 \%$ to the secondary education category, and $10 \%$ to the tertiary education category. The multi-state educational pro-

7 These comparisons are also influenced by the different age compositions of women in the various educational groups.

8 The aggregate total fertility rate for the period 1995-2000 by region was calculated from United Nations (1999) country estimates of age-specific fertility rates weighted by number of women by age.

9 Information on sources of data is given in the Appendix. 
jections also require data on the transition of children from one level of school attainment to another. In our model all children are born into the no-education category. Transition rates between educational categories for the starting period were calculated and estimated on the basis of the most recently available levels of educational attainment and enrollment rates for age groups 5-9, 10-14, 15-19, and 20-24.

Assumed future trends in the aggregate levels (i.e., over all educational groups) of fertility, mortality, and migration for each world region follow the new IIASA world population projections and are extensively documented and justified elsewhere (Lutz 2001). The future educational fertility differentials are assumed to follow an algorithm yielding gradually diminishing differentials as the level of fertility falls. Future transition rates from one educational group to the next are subject to alternative scenario assumptions as discussed below.

\section{Results}

Two scenarios are presented here. The "constant transition rates" (or "constant") scenario assumes that no improvements are made over time in the proportion of a young cohort that acquires different levels of education, while fertility, mortality, and migration trends follow the IIASA central scenario as discussed above. The "convergence to Northern American transition rates by 2030" (or "American") scenario assumes that all regions experience linear improvements in their enrollment that will bring them by 2025-30 to the school enrollment levels of Northern America today. All children will receive at least some primary education, and up to $98 \%$ will receive some secondary education. Participation in tertiary education will increase to $55 \%$. The "American" scenario also implies closing the gender gap at all educational levels by 2030 .

Figure 2 gives the starting conditions in 2000 and the results of the two alternative scenarios in 2030 for the aggregate world population. Information is given in the form of multi-state age pyramids for women in five-year age groups on the right and men on the left, with the shading referring to different levels of educational attainment. The improvements in schooling over the past 20 years are clearly visible in the form of smaller proportions without formal education in the younger cohorts. But the figure also shows that a wide gender gap in education still exists at the global level. The longer-term implications of this are visible in the second pyramid giving the results of the "constant" scenario for 2030. Because of past declines and anticipated future declines in fertility, the age structure of the world is expected to grow older. In terms of education the "constant" scenario preserves the gender bias in the current educational system. The "American" scenario in contrast shows another possible future in which, over the coming 30 years, Northern American enrollment rates are being approached. This would significantly increase the educational attainment of the world population below age 30 and narrow the educational gender gap. The older labor force will not yet be affected by 2030 . This illustrates the slow speed at which recent and current investments in education will affect the educational composition of the total population.

Specific regional comparisons are much more informative than the global averages. Figure 3 compares the female population of China (plus centrally planned Asia) with that of South Asia (mostly India). The pyramids have an unusual shape because they compare regions rather than men and women. Although in 2000 China and South Asia are roughly 
Figure 2: Population by age and sex and by estimated level of education for the world in 2000 and projected figures for $\mathbf{2 0 3 0}$ according to the "constant" and "American" scenarios (millions)
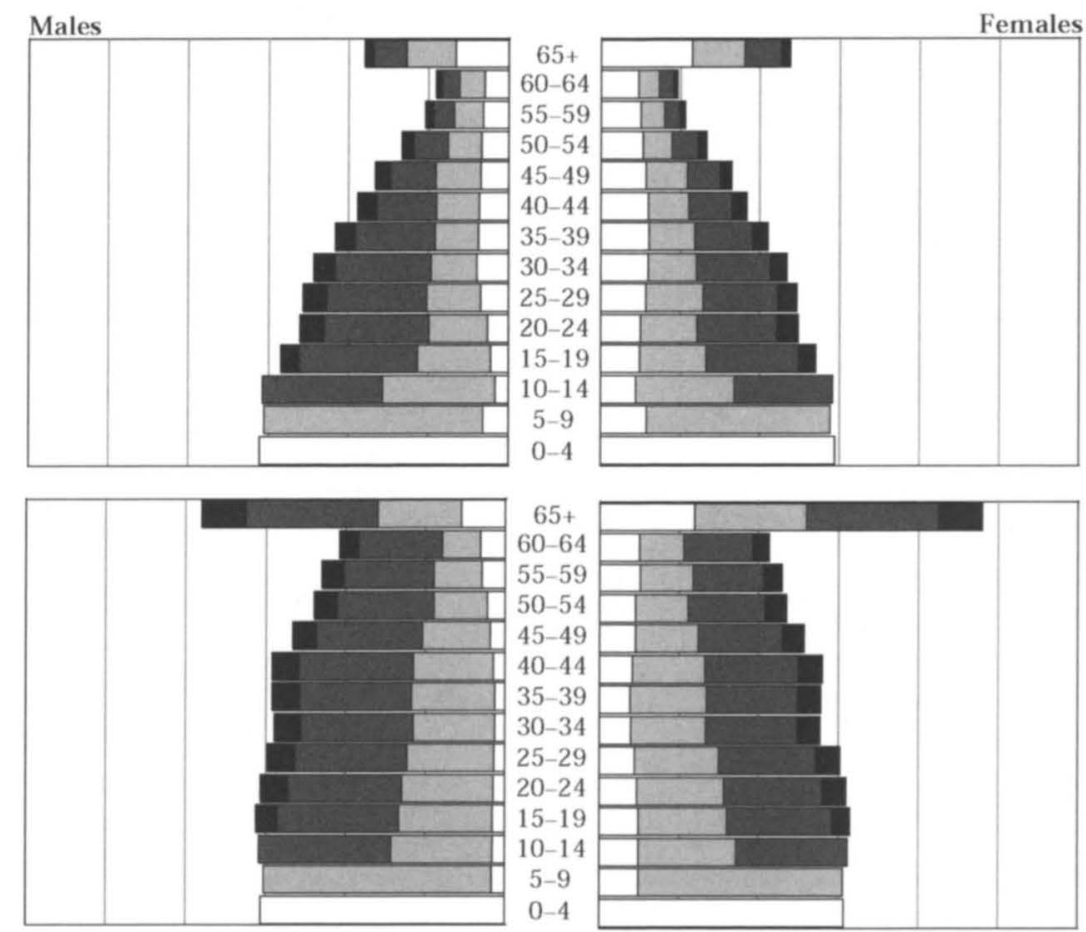

2030

"Constant" scenario
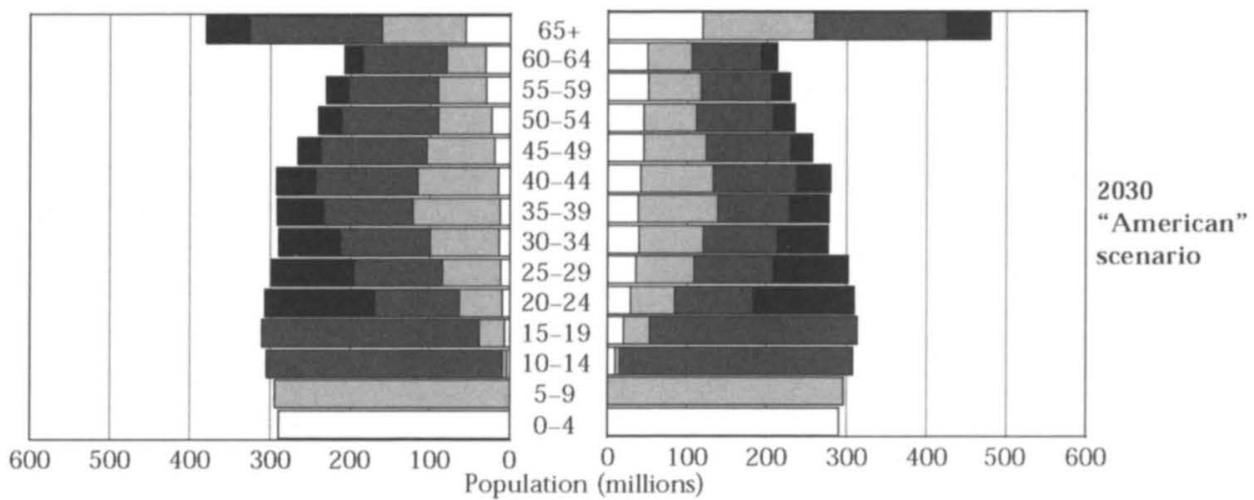

No education

Primary

Secondary

Tertiary

equal in terms of total population size, the Chinese age structure clearly shows the effects of fertility decline over the past three decades and, more importantly for our context, shows the major investments China made in female education as compared to South Asia. The results for 2030 also demonstrate that this legacy of the past three decades cannot be fully overcome in the next three decades, even under the unlikely assumption of attainment of Northern American school enrollment rates in India. 
Figure 3: Female population by age and by estimated level of education in China (plus centrally planned Asia) and South Asia in 2000 and projected figures for 2030 according to the "constant" and "American" scenarios (millions)

China and centrally planned Asia
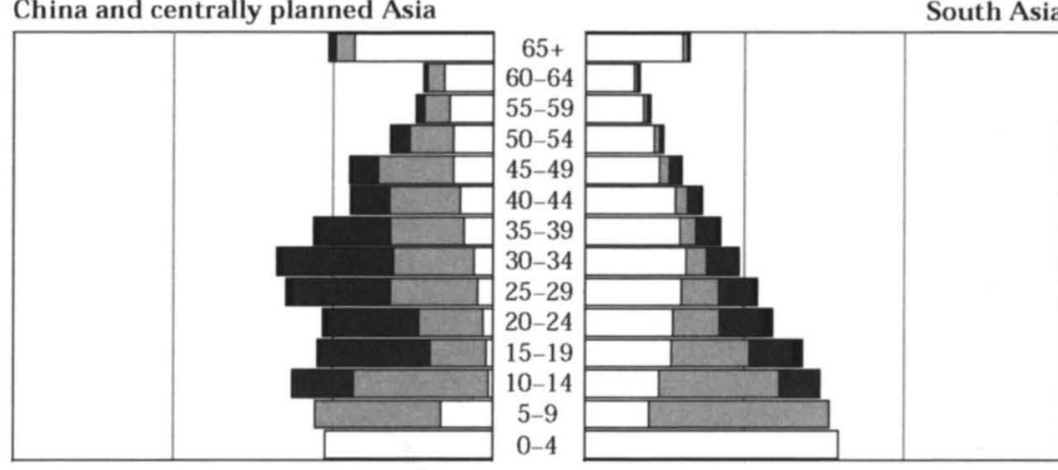

2000
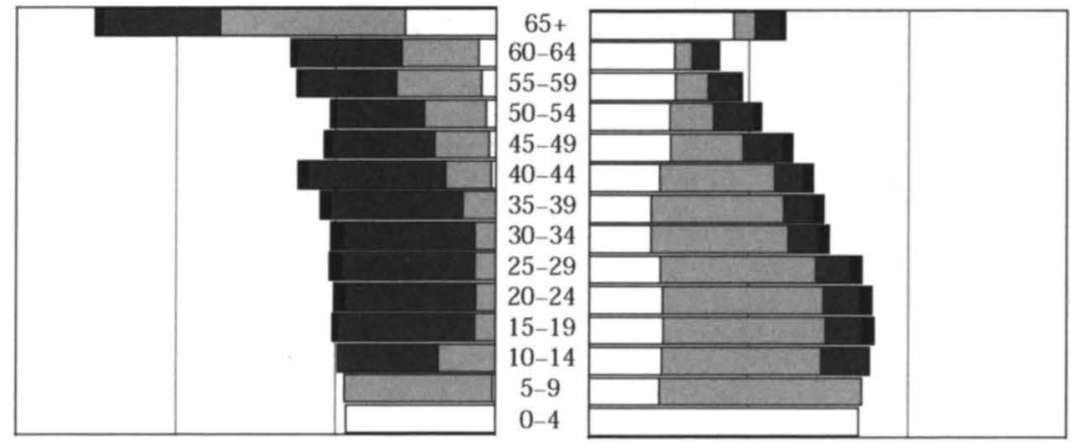

2030

"Constant"

scenario

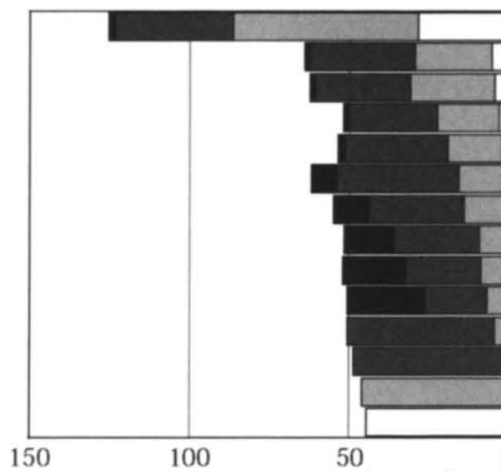

$65+$

60-64

$55-59$
$50-54$

$45-49$

$40-44$

$35-39$
$30-34$

$25-29$

$20-24$

$15-19$

10-14

5-9

0-4

Population (millions)

No education

Primary

- Secondary

"American" scenario

As comparisons based on Tables 1 and 2 show, some regions are likely to see remarkable progress even in the case of the "constant" scenario. Most impressive is the case of China, where the proportion of women above age 15 with secondary education would increase from $35 \%$ in 2000 to $60 \%$ in 2030 and that of men from $51 \%$ to $71 \%$. In North Africa and West Asia, the proportion of women with secondary education would increase from $20 \%$ and $23 \%$, respectively, in 2000 to $35 \%$ and $37 \%$ in 2030 . These expected im- 
provements are a direct consequence of past investments in female education. In sub-Saharan Africa only minor improvements in educational attainment can be expected because of this time-lag effect in the transformation of the composition of the overall population. In a number of African countries recent declines in school enrollment rates even imply a deterioration of the educational composition in the long run.

On a global level the "constant" scenario implies that in $203018 \%$ of women above age 15 will still be without any formal education, hence will be mostly illiterate. For men this share is only $8 \%$. Under the "American" scenario, the share without formal education would only decline to $16 \%$ for women and $7 \%$ for men by 2030 . This slow improvement at the lower educational end of the adult population is again attributable to the great inertia of the transformation of the educational composition of a population over time. It also shows that the officially adopted benchmarks for achieving goals set at the 1994 International Conference on Population and Development in Cairo (United Nations 2000), which include halving female illiteracy within 15 years, that is, by 2010, are unrealistic. Even under the very optimistic "American" scenario, this proportion will not be halved until around 2030. For tertiary education, the results of countries' efforts become visible more quickly. While presently $8 \%$ of all women and $11 \%$ of all men in the world have some tertiary education, by 2030 this would increase to only $10 \%$ and $12 \%$, respectively, under the "constant" scenario, but to $17 \%$ and $19 \%$ under the "American" scenario.

We now point to the results of one special scenario that incorporates a second-order feedback, from mothers' level of education to girls' enrollment ratios, which goes beyond the first-order feedbacks (compositional effects) of the "constant" and "American" scenarios. Taking the "American" scenario as a basis, this special scenario assumes that the educational transition rate for secondary and tertiary education in any five-year period increases/decreases by the same rate as the change in the proportion of women with secondary and tertiary education in certain age groups (ages 30-39 for secondary education and 40-49 for tertiary education) as compared to the previous period. This self-reinforcing feedback mechanism is assumed to cover both the intergenerational transmission of education and the fact that better-educated populations tend to be more productive and in turn invest more in education. The results, given in Table 4, are compared to the "constant" and "American" scenarios for the female population aged 20-64 in China (and centrally planned Asia) and South Asia. Because primary enrollment was not made subject to this feedback mechanism (the "American" scenario already assumes a strong trend to universal enrollment), the proportions with no education in 2030 are identical in both scenarios. This proportion is almost ten times larger in South Asia than in China. For the higher educational groups this reinforcing feedback mechanism results in a clear further improvement of the educational attainment structure in China, whereas in South Asia it results in some interesting bifurcation. As compared to the "American" scenario, the proportions in South Asia with primary and tertiary education increase, while the proportion with secondary education declines. This may partly reflect the bifurcation in Indian society, where the assumed intergenerational transfer in education tends to produce a sizable highly educated elite on the one hand, and a large group with lower education on the other, with the intermediate group of secondary education diminishing.

The changing educational composition of the population is significant not only for individual development and a country's social progress and economic performance, but also for the relative weights, productivity, and competitiveness of major world markets. In this context it is useful to look at absolute numbers of workers by skill levels rather than at the proportions with given levels of education. Figure 4 compares three economic mega- 
Table 4: Estimated educational composition (in \%) of the female population aged 20-64 in 2000 and projected composition in 2030 according to a special scenario considering feedback from changes in the proportions of educated mothers to the secondary and tertiary enrollment ratios of girls, compared to the "constant" and "American" scenarios for the China region and South Asia

\begin{tabular}{|l|c|c|c|c|}
\hline & \multirow{2}{*}{$\mathbf{2 0 0 0}$} & \multicolumn{3}{|c|}{$\mathbf{2 0 3 0}$} \\
\cline { 3 - 5 } & & $\begin{array}{c}\text { "American" } \\
\text { with feedback }\end{array}$ & "Constant" & "American" \\
\hline China region & 21.5 & 3.6 & 3.4 & 3.6 \\
$\quad$ No education & 41.0 & 25.5 & 26.0 & 27.8 \\
Primary & 35.3 & 50.9 & 65.5 & 51.5 \\
Secondary & 2.2 & 20.0 & 5.1 & 17.0 \\
Tertiary & & & & \\
South Asia & 68.1 & 33.0 & 35.3 & 33.0 \\
No education & 14.6 & 38.6 & 45.4 & 36.7 \\
Primary & 15.3 & 13.5 & 15.7 & 18.6 \\
Secondary & 1.9 & 14.9 & 3.7 & 11.7 \\
Tertiary & & & & \\
\hline
\end{tabular}

Note: For countries included in China region see note to Table 1.

Figure 4: Estimated population aged 20-64 years (in millions) by levels of education, according to the "American" scenario, 2000-30, in three economic mega-regions

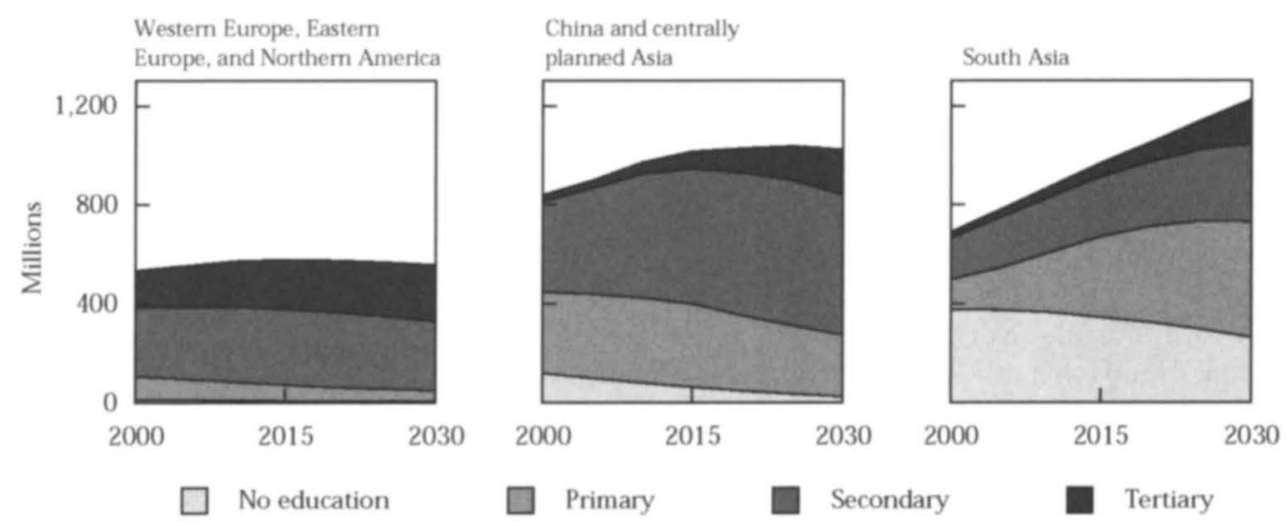

regions of the present and future (Europe and Northern America together, China and centrally planned Asia, and South Asia) in terms of trends in the size of the working-age population (age 20-64) by educational attainment. The data are taken from the "American" scenario. At present China clearly has the most numerous working-age population of these three regions, but its educated population (secondary and tertiary together) is still smaller than that of Europe and Northern America combined. In terms of the educated workingage population, South Asia is far behind, with less than half the size of the other two 
regions. Over the next 20 years, South Asia is expected to surpass China in the total size of the working-age population. But in terms of the educational composition of the population, the difference between the two regions will be striking. While in China in 2030, some $73 \%$ of the working-age population will be better educated (secondary plus tertiary), the fraction in South Asia will be only $40 \%$. The main reason for this divergence lies in the differences between the two regions in their investment in primary and secondary education over the last two decades. Among the three major world regions, Europe and Northern America will continue to have the highest educational levels of their working-age populations, but in terms of absolute numbers of educated people will clearly fall behind China. Over the next three decades China's educated working-age population is likely to increase from 390 million to 750 million, while that of Europe (without the former Soviet Union) and Northern America together will increase from 430 million to 510 million in 2030. These future changes in the numbers of skilled workers are likely to have far-reaching consequences for relative weights in the global economic system.

In terms of policy priorities, this study has demonstrated numerically the importance of near-term investments in education for the long-term human resources of a country, thus confirming an often-held qualitative view. There is convincing evidence (e.g., Lutz 1994) that, of countries that were at comparable stages of development in the 1960 s, those that invested heavily in education do better today by virtually all health and development indicators. Inversely, cutting back on education and even risking declining enrollment rates, as has happened in many countries in the course of structural adjustment programs, is detrimental to a population's long-term future.

\section{Appendix: Sources of data and methods of estimation}

The regional decomposition by levels of educational attainment was based on individual country data. These were extracted mainly from the UNESCO Statistical Yearbook (1995), but also from the OECD Education Database 1999; the EUROSTAT Data Base; Demographic and Health Surveys, 1988-98; the League of Arab States PAPCHILD Project, 1990 s; and several country censuses. (Detailed information on the source for each country is available from the authors by request: goujon@iiasa.ac.at) Data obtained from UNESCO yearbooks on the adult population according to the highest level of education attained were collected during national population censuses or sample surveys. UNESCO presents the data available from the latest census or survey held since 1979; they are either provided by the United Nations Statistical Office or derived from national publications. The range of countries included was representative of each region and was aimed at maximum coverage. The regional coverage was estimated at more than $95 \%$ of the total population in 2000 for China and centrally planned Asia, Northern America, Pacific Asia, Pacific OECD, and South Asia. The coverage was between 84 and $89 \%$ for Central Asia, Eastern Europe, former Soviet Union, Latin America and the Caribbean, and Western Europe. In the three remaining regions, West Asia, North Africa, and sub-Saharan Africa, the coverage was between 60 and $80 \%$.

Some adjustments had to be made to the data to make them conform to the format needed for the projections. These were mostly of two sorts. First, adjusting the data to fit 
the 2000 base year was required in most cases unless educational composition was available for the period 1996-2000. The age groups were moved up to reflect the aging of the population. For instance, if the population in the age group 20-24 was available for 1990 for Pakistan by education, the data were shifted to the age group 30-34 for the year 2000, and so on, for all age groups. The second adjustment that was often needed was related to data not available for all age groups. Sometimes the educational attainment of the population is available for age groups broader than the five-year age groups used for the projections. In this case the same educational decomposition was used for the broader age groups as for the narrower age groups. Education data were often missing for younger age groups up to 25 years of age. The missing data were then approximated by using data on enrollment at different periods of time; such data are usually provided by UNESCO in its yearbooks.

\section{References}

Ahuja, Vinod and Deon Filmer (1995): Educational attainment in developing countries: New estimates and projections disaggregated by gender. Washington, DC: World Bank (mimeo.).

Barro, Robert and Jong-Wha Lee (1993): International comparisons of educational attainment. Journal of Monetary Economics 32(3), pp. 363-394.

Bellew, Rosemary, Laura Raney, and K. Subbarao (1992): Educating girls. Finance and Development 29(1), pp. 54-56.

Benavot, Aaron (1989): Education, gender, and economic development: A cross-national study. Sociology of Education 62, pp. 14-32.

Bongaarts, John and Rodolfo A. Bulatao (eds.) (2000): Beyond Six Billion: Forecasting the World's Population. Washington, DC: National Academy Press.

Brock, Colin and Nadine Cammish (1997): Gender, Education and Development: A Partially Annotated and Selective Bibliography. London: Department for International Development.

Dubey, Ashutosh and Elizabeth King (1994): A new cross-country education stock series differentiated by age and sex. Washington, DC: World Bank (typescript).

Federici, Nora, Karen Oppenheim Mason, and Sølvi Sogner (1993): Women's Position and Demographic Change. Oxford: Clarendon Press.

Grossman, G.M. and E. Helpman (1991): Innovation and Growth in the Global Economy. Cambridge, MA: MIT Press.

Hadden, Kenneth and Bruce London (1996): Educating girls in the third world: The demographic, basic needs, and economic benefits. International Journal of Comparative Sociology 37(1-2), pp. $31-47$.

Jejeebhoy, Shireen J. (1995): Women's Education, Autonomy, and Reproductive Behaviour: Experience from Developing Countries. Oxford: Clarendon Press.

Keyfitz, Nathan (1985): Applied Mathematical Demography. 2nd edition. New York: SpringerVerlag.

Kyriacou, G.A. (1991): Level and growth effects of human capital: A cross-country study of the convergence hypothesis. Department of Economics, New York University (mimeo.).

Lutz, Wolfgang (1994): Lessons from Mauritius in the global context. In: Wolfgang Lutz (ed.), Population-Development-Environment: Understanding Their Interactions in Mauritius. Berlin: Springer-Verlag, pp. 361-385.

Lutz, Wolfgang (ed.) (1996): The Future Population of the World: What Can We Assume Today? Revised Edition. London: Earthscan.

Lutz, Wolfgang (ed.) (2001): Population Balance: Population Distributions, Human Capital and Sustainable Development in the 21st Century. Draft book manuscript. Laxenburg, Austria: International Institute for Applied Systems Analysis. 
Lutz, Wolfgang, Anne Goujon, and Gabriele Doblhammer-Reiter (1999): Demographic dimensions in forecasting: Adding education to age and sex. In: Wolfgang Lutz, James W. Vaupel, and Dennis A. Ahlburg (eds.), Frontiers of Population Forecasting. Supplement to Population and Development Review, 24. New York: Population Council, pp. 42-58.

Lutz, Wolfgang, James W. Vaupel, and Dennis A. Ahlburg (eds.) (1999): Frontiers of Population Forecasting. Supplement to Population and Development Review, 24. New York: Population Council.

Mankiw, N.G., David Romer, and David N. Weil (1992): A contribution to the empirics of economic growth. Quarterly Journal of Economics 107(2), pp. 407-437.

Nehru, Vikram, Eric Swanson, and Ashutosh Dubey (1993): A new database on human capital stock: Sources, methodology and results. Policy Research Working Paper 1124. Washington, DC: World Bank.

OECD (1999): Education at a Glance, Database. CD-ROM. Paris: OECD.

Psacharopoulos, George and Ana Maria Arrigada (1986): The educational composition of the labor force: An international comparison. International Labor Review 125(5), pp. 561-574.

Psacharopoulos, George and Ana Maria Arrigada (1992): The educational composition of the labor force: An international update. Journal of Educational Planning and Administration 6(2), pp. $141-159$.

Rogers, Andrei (1975): Introduction to Multiregional Mathematical Demography. New York: John Wiley.

Romer, P.M. (1989): Human capital and growth: Theory and evidence. NBER Working Paper 3173. Cambridge, MA: National Bureau of Economic Research.

Romer, P.M. (1992): Two strategies for economic development: Using ideas and producing ideas. In: L.H. Summers and S. Shah (eds.), Proceedings of the World Bank Annual Conference on Development Economics. Washington, DC: World Bank, pp. 63-115.

UNESCO (1995): Statistical Yearbook. Paris.

United Nations (1999): World Population Prospects: The 1998 Revision. New York.

United Nations (2000): Annex 1. Page 17 of the Executive Board of the United Nations Development Programme and of the United Nations Population Fund, "Future Programme Directions of UNFPA in Light of the Outcome of the Five-year Review of the International Conference on Population and Development $(\mathrm{ICPD}+5)$." New York: United Nations, DP/FPA/2000/9. 